\title{
Formação de professores de inglês pré-serviço em Alagoas: uma reflexão sobre identidades
}

\section{Pre-Service English Teachers' Education in Alagoas: a Reflection on Identities}

\author{
Paulo Rogério Stella* \\ Universidade Federal de Alagoas \\ Maceió - Alagoas / Brasil \\ Daniel Adelino Costa Oliveira da Cruz ${ }^{* *}$ \\ Universidade Federal de Alagoas \\ Maceió - Alagoas / Brasil
}

RESUMO: Este artigo reflete sobre a formação de professores de língua inglesa em situação pré-serviço no estado de Alagoas com base em noções de identidade e alteridade (PONZIO, 2010). Ao observarmos o contexto atual de ensino e aprendizagem dessa língua no estado, percebemos a presença de valores (BAKHTIN / VOLOCHINOV, [1926] 2000) negativos na identidade de professor dos graduandos que estão ingressando no ensino público, o que interfere diretamente em suas práticas de sala de aula. Propomos, então, um trabalho baseado em narrativas pessoais (WEBSTER; MERTOVA, 2007) com o objetivo da construção de alteridades firmes. Desse modo, temos a expectativa de que nossos graduandos em situação pré-serviço não percam de vista os valores positivos da educação e consequentemente não sucumbam às pressões contextuais.

PALAVRAS-CHAVE: identidade, alteridade, ensino e aprendizagem de língua inglesa, graduandos.

ABSTRACT: This article reflects on pre-service English teachers' education in the state of Alagoas based on the notions of identity and otherness (PONZIO, 2010). Upon observing the present context of teaching and learning this language in the state, we have noticed the presence of negative values (BAKHTIN / VOLOCHINOV, [1926] 2000) in the teacher's identity of our undergraduate students who were about to begin teaching in public schools, which interfered directly in their class practices. We, then, propose a study of the issue of personal

* prstella@me.com

**danielcostacruz@uol.com.br 
narratives (WEBSTER; MERTOVA, 2007) whose objective is the construction of firm otherness. In this manner, it is expected that the undergraduates from our institution in pre-service training, who enter public education in the state, do not lose track of the positive values of education and, consequently, do not give in to contextual pressures.

KEYWORDS: identity, otherness, teaching and learning English, undergraduates in pre service training.

\section{Introdução}

Este artigo discute questôes relacionadas à identidade de alunos graduandos do curso de Licenciatura em Letras-Inglês da Faculdade de Letras da Universidade Federal de Alagoas, portanto, em situação de pré-serviço. Como estão iniciando suas vidas como professores de língua inglesa (doravante LI) na escola pública básica regular, podem ser suscetíveis às pressões do contexto árido do ensino público no estado. Queremos dizer com isso que a identidade de professor de Inglês desses futuros professores é diretamente afetada pelo contexto, o que interfere diretamente em suas práticas de sala de aula, apesar do trabalho de formação em situação de pré-serviço pelos quais todos os alunos passam durante a graduação, incluindo, entre outras coisas, $o$ estágio supervisionado. Dito de outro modo, nossos dados indicam que os resultados apresentados por nossos graduandos, ao ingressarem efetivamente em sala de aula como professores, são bastante negativos.

Nosso conjunto de dados advêm de pesquisas durante 2012 no âmbito do Núcleo Alagoas ou Projeto de Formação de Professores de Inglês no Estado de Alagoas ${ }^{1}$ cujo objetivo geral é o auxílio à formação continuada de professores de LI em escolas públicas do ensino básico regular de Alagoas a partir das teorias dos novos letramentos e multiletramentos. O recorte focalizado neste trabalho refere-se aos resultados de entrevistas com 20

${ }^{1}$ O Núcleo Alagoas faz parte do Projeto de Formação de Professores nas Teorias dos Novos Letramentos e Multiletramentos, também conhecido como Projeto Nacional de Formação de Professores, sediado na Universidade de São Paulo. O Núcleo está ligado ao grupo de pesquisa Observatório da Linguagem em Uso (ObservU), liderado pela Profa. Dra. Roseanne Rocha Tavares, registrado no $\mathrm{CNPq}(<>)$, que objetiva a produção de conhecimentos sobre as relaçóes entre linguagem, cultura e formação de professores no estado. O Núcleo Alagoas também é mantido pelo Núcleo de Estudos em Línguas e Literaturas Estrangeiras (NELLE), presidido pelo Prof. Me. Daniel Adelino Costa Oliveira da Cruz, cujo objetivo é produzir conhecimento sobre línguas e literaturas estrangeiras. 
professores de LI de escolas públicas objetivando o mapeamento da formação, das práticas em sala de aula e das epistemologias adotadas por eles. Além disso, inserimos alguns relatos e diários dos graduandos participantes do processo sobre suas percepçóes a respeito de aulas assistidas dos entrevistados como complemento das entrevistas. Incluímos também como forma de construir o contexto de nosso trabalho, os resultados de entrevistas feitas com 100 alunos da disciplina de Inglês do ensino fundamental e médio sobre suas percepções a respeito da aprendizagem dessa língua. Por fim, o conjunto de dados completa-se com as narrativas dos graduandos acerca da própria construção identitária em relação ao ensino e aprendizagem de LI, foco de nosso artigo.

Esse texto integra ainda o conjunto de reflexōes da linha de pesquisa de Linguística Aplicada do Programa de Pós-Graduação em Letras e Linguística da UFAL. Os participantes dessa linha entendem que a Linguística Aplicada (LA) não pode e não deve posicionar-se ao lado da neutralidade científica ficando alheia aos problemas que se colocam, porque, em sendo a LA uma ciência cujo instrumento é a linguagem e em sendo a linguagem constitutiva da dimensão humana, a modificação das práticas estabelecidas somente pode ser possível por meio da reflexão na e sobre a própria linguagem que as diz. Com isso afirmamos que a LA tem uma função ativa na tomada de posição contra os desequilíbrios ocasionados, segundo Pennycook (1998), pelas desigualdades sociais sérias trazidas em consequência da globalização e da tecnologização, impedindo o acesso de muitos à educação, à saúde e à segurança ao mesmo tempo em que oferece privilégios a poucos.

Nosso ponto de vista engloba três vieses teóricos principais que se entrelaçam no decorrer das reflexões apresentadas. $O$ primeiro constitui-se por meio da relação entre identidade e alteridade, ou seja, ao mesmo tempo que nossas identidades fixam-se dentro dos grupos a que pertencemos, essas mesmas identidades somente solidificam-se por meio de valores constituídos pela percepção acerca de nossa singularidade no mundo (PONZIO, 2010). O segundo viés trata do sentido de interlocução (BAKHTIN, [1979] 2003), que visa à produção de sentidos por meio de interações significativas entre interlocutores. O terceiro viés teórico reflete acerca da importância dessas interações na possibilidade de reposicionamento dos interlocutores em relação a seus valores (BAKHTIN / VOLOCHINOV, [1926] 2000), percebidos nos processos alteritários dentro das interaçôes.

$\mathrm{Na}$ tentativa de dar a coerência demandada pela linearidade do texto escrito, propomos organizar este artigo em três seções distintas, mas que se completam em um todo de sentido, além desta introdução, das considerações 
finais e das referências. A primeira seção discute questões de identidade dos professores de Inglês nas escolas públicas em Alagoas, propondo entender melhor qual é ou quais são essas identidades por meio de uma análise do contexto de atuação desses professores. A seção seguinte discute o problema da entrada dos graduandos em sala de aula como professores e os resultados disso na constituição de suas identidades em decorrência da interferência do contexto agressivo em que se inserem. Por último, apresentamos o trabalho com o que denominamos de processo narrativo dos alunos, propondo a construção de valores por meio do diálogo, entendido de forma mais complexa, o que pode vir a ajudar na interação com o contexto em que pertencerão ao assumirem efetivamente uma sala de aula.

\section{O contexto de Alagoas na construção da identidade coletiva dos professores de LI}

Em discussão sobre as relações de poder nas instituiçōes, Fairclough (2003) estabelece uma ligação entre a manutenção dessas relaçôes e as práticas discursivas circulantes. $\mathrm{O}$ autor entende que a linguagem circulante nas instituiçōes garante a manutenção das estruturas de poder por meio da transmissão contínua dos valores circulantes, permitindo não somente a sensação de estabilidade e de naturalidade dos sentidos, mas também a reprodução, sustentação e transmissão dessas práticas, o que determina a própria sobrevivência das instituiçōes, além da naturalização dos poderes constituídos.

Na mesma esteira de discussão, Bakhtin / Volochinov ([1929] 2010) fazemnos refletir sobre a relação entre língua e transmissão de valores ao discutirem os processos de inserção dos discursos alheios em nosso próprio discurso. Para os autores, há vários graus de apreensão de discursos de outro pelo falante, sendo o nível máximo caracterizado pela não percepção do falante da participação desse outro em sua própria fala, fazendo do discurso alheio aquele do próprio falante. Nesse momento, o falante assimila não somente as palavras do outro, mas também os valores circulantes e válidos, o que garante a perpetuação desses valores no contexto a que pertencem. Percebe-se que esse processo de assimilação das palavras e dos valores do outro liga-se intimamente à construção de identidades. Bakhtin ([1979] 2003) entende que o falante é, ao mesmo tempo, responsivo em relação às demandas discursivas que lhe são impostas nos processos de interação e responsável por aquilo que diz, o que torna o falante autor de seu próprio discurso e, por conseguinte, identifica-o como membro de grupos por onde estes discursos, integrados à fala do falante, circulam. 
Esse ponto de vista parece-nos bastante produtivo no tratamento dos discursos circulantes no estado de Alagoas sobre ensino e aprendizagem de LI no espaço público, pois ajuda-nos a pensar a identidade do professor, considerando que há discursos que circulam dentro e fora desse espaço não somente sobre o ensino público em geral e sobre a LI especificamente, mas também sobre as práticas adotadas dentro de sala de aula. Em outras palavras, esses discursos apontam para valores como descaso, ineficiência e desmotivação para a mudança, concretizados não somente nas políticas públicas que pouco existem no estado, mas também nos cursos de formação de professores que sofrem com a falta de alunos. Além disso, percebermos esses mesmos valores nas falas de professores e de alunos quando se referem ao ensino e aprendizagem dessa língua estrangeira.

Iniciaremos nossa discussão com as políticas públicas para o ensino de LI, cabendo algumas explicações sobre o contexto socioeconômico da região. O estado de Alagoas se posiciona entre os estados com os piores índices sociais, econômicos e educacionais no Nordeste e, consequentemente, no Brasil. De acordo com o portal Todos Pela Educação, do Governo Federal, enquanto a renda per capita domiciliar média do brasileiro é de $\mathrm{R} \$ 668,00$, em Alagoas essa média fica em $\mathrm{R} \$ 378,00$ (dados de 2010), o que coloca o estado na antepenúltima posição entre os estados brasileiros. ${ }^{2}$

No que se refere à educação básica, os dados do censo 2010 do IBGE mostram que $22,5 \%$ dos aproximadamente 3,2 milhões de habitantes declaram-se analfabetos; índice muito acima da média nacional de $9 \%$. Além disso, a média brasileira de crianças em atraso escolar de dois anos ou mais é de $12 \%$, enquanto em Alagoas essa média sobe para 25,5\%. Nesse contexto, ainda de acordo com o mesmo informativo, $65 \%$ dos estudantes de ensino fundamental e médio não terminam seus cursos na idade idealmente esperada, quando os terminam.

O Índice de Desenvolvimento da Educação Básica (IDEB), que mede a qualidade da educação no Brasil por meio da atribuição de conceitos, estabelece um índice de 2,7 em Alagoas para as séries finais do fundamental público. Se comparado à média nacional de 3,7 , que já é baixa em relação aos países considerados desenvolvidos cuja média é 6,0, podemos inferir que há uma grande lacuna na qualidade de ensino na regiáo, posicionando Alagoas em último lugar entre os estados brasileiros nesse quesito (IDEB, 2012).

${ }^{2}$ http://goo.gl/XFTzAI 
Esse contexto reflete a quase inexistência de políticas públicas para a educação básica em geral, havendo, por isso, poucas ações efetivas de fomento à formação continuada dos professores de LI do ensino público. Há propostas que não saem do papel pela dificuldade em se conseguir qualquer incentivo, seja a projetos de intervenção dos professores em suas salas de aula, seja a quaisquer outras ações de desenvolvimento linguístico desses professores. Concretamente, as aulas de LI são ofertadas como complemento de carga horária a professores de outras disciplinas que se disponham a dá-las, o que provoca tanto uma descaracterização quanto um esvaziamento da necessidade do aprendizado dessa língua.

Vale a pena dizer que além dos professores habilitados em Inglês, há também uma boa quantidade de professores de Matemática e de Geografia ministrando a disciplina de LI. Não bastando, e em consequência da inexistência de tais políticas, ainda há uma enorme defasagem de professores para todas as disciplinas e, especialmente, de professores de LI. Isso foi compensado em 2012 por interferência do Ministério Público com um concurso público para monitores, que são graduandos de cursos de licenciatura com mais de $50 \%$ de créditos cumpridos, para trabalho por tempo determinado de dois anos no ensino fundamental II e médio no estado. Registre-se que esses monitores não tinham recebido o primeiro pagamento por seus serviços até março de 2013. Em entrevista ao Núcleo Alagoas, um professor da escola pública com formação em Inglês e Português resume sua percepção sobre a importância da disciplina nesse contexto: "acho importantíssimo, embora ache também que não se dá o devido valor a esta disciplina” (NÚCLEO, 2012, p. 23).

Certamente, esse contexto apresentado reflete-se diretamente nos valores trazidos à sala de aula nas escolas públicas pesquisadas. Os resultados de nossa pesquisa apontam que $45 \%$ do tempo de aprendizado de língua é ocupado pelo ensino da gramática tradicional, $20 \%$ por tradução de sentenças, $15 \%$ por leitura de textos simples, $10 \%$ por exercícios de pronúncia e os outros $10 \%$ restantes são divididos em escrita, conversação e audição. Esse foco na gramática pode ser confirmado pelo depoimento de um professor entrevistado que afirma que "pelo fato da universidade receber alunos com pouca fluência no que diz respeito à aprendizagem de língua inglesa, acabavam focando os objetivos das aulas no ensino de gramática mesmo" (NÚCLEO, 2012, p. 23).

Em referência às metodologias adotadas, $34 \%$ dos professores entrevistados utilizam o que chamam de método tradicional e $23 \%$ utilizam a gramática contextualizada. Trataremos, primeiramente, do sentido de 
gramática contextualizada, deixando um espaço maior para a reflexão do que é método tradicional. Um professor explica o que entende por gramática contextualizada dizendo que "apresenta as estruturas gramaticais de forma contextualizada", definindo o termo "contextualizada" por "explicitação do ponto gramatical para os alunos entenderem melhor" (NÚCLEO, 2012, p. 32 ). Outros $23 \%$ ensinam com várias metodologias ao mesmo tempo. Um dos professores explica o que entende por isso: "costumo mesclar o ensino de língua estrangeira na sala de aula, utilizo a abordagem comunicativa assim que inicio a aula, o método tradicional para explicar a estrutura gramatical, o método áudio-lingual com a repetiçãa" (NÚCLEO, 2012, p. 33). O método audiolingual é utilizado por $10 \%$ dos professores, assim como a abordagem comunicativa. Ambos, contudo, não são claramente definidos pelos professores, mas podem ser associados a atividades de repetição e leitura em voz alta. Um professor descreve o método audiolingual como drills e a abordagem comunicativa como a possibilidade de os alunos pedirem "para ir ao banheiro ou beber água, bem como na oralidade dos diálogos [do livro]" (NÚCLEO, 2012, p. 33).

Deixamos um espaço maior para a discussão do sentido do método tradicional porque a maioria dos professores diz utilizá-lo direta ou indiretamente. Para esta reflexão, traremos um relato de observação de aula feito por um dos alunos do curso de Letras Licenciatura em Inglês participante da pesquisa. Uma professora com formação em Letras com dupla habilitação em Inglês e Português explica que utiliza o "método tradicional, porque é mais fácil para os alunos” (NÚCLEO, 2012, p. 27). Fica a pergunta, então: o que significa "método tradicional" nesse contexto educacional?

A observação da aula dessa professora ajuda-nos a entender o sentido de tradicional. A professora inicia a aula colocando na lousa seis orações em língua inglesa para serem completadas com o verbo ser (to be) no presente do indicativo, duas delas para serem completadas com a terceira pessoa do singular, duas com a segunda pessoa e duas com o plural. Depois, a professora coloca o paradigma verbal do verbo to be no presente do indicativo na lousa, lê em voz alta e pede que os alunos repitam-no. Dá um tempo para os alunos completarem as oraçôes com os verbos faltantes. Corrige as sentenças, pedindo que um aluno por vez dirija-se à lousa para preencher um dos espaços com um verbo corretamente conjugado. Por fim, pede a tradução das orações. A aula termina sem que a correção das traduções tenha sido feita.

Com exceção dos poucos momentos em que a professora escreve na lousa, durante todo o tempo, ela permanece sentada a sua mesa observando 
os alunos trabalharem enfileirados. À medida que alguns alunos conversam, a professora demanda silêncio, chamando a atenção novamente para as sentenças na lousa. Uma das orações escritas pela professora continha a palavra house. No trabalho de tradução, um dos alunos levanta a mão e pergunta o que significa $L A N$ house. A professora para o que está fazendo, levanta-se e escreve na lousa: lã e house. Em seguida, responde que house é casa, mas lã ela não sabe dizer nem o significado nem porque acompanha a palavra casa em inglês. A aula continua.

Sobre a percepção dos professores em relação a sua prática de sala de aula, os resultados não são muito melhores do que as observações sobre os métodos utilizados. Percebem que a LI é importante no contexto global, para tanto se referem à globalização e ao mercado de trabalho para explicarem que o inglês tem um papel fundamental nesses dois contextos. Por outro lado, não identificam a escola pública como o local mais adequado para a aprendizagem dessa língua porque consideram que há desinteresse por parte dos alunos pelo aprendizado e falta de estímulo aos professores. Nas palavras de um dos professores entrevistados para o Núcleo Alagoas:

O ensino de inglês é muito importante na escola pública, pois é uma forma de incluir as classes mais baixas em uma sociedade tão globalizada. No entanto esse ensino precisa ser repensado, visto que o inglês como disciplina ainda é muito desvalorizado, até mesmo alguns professores, em seus discursos, afirmam que não têm estímulos para ensinar pelo fato de ser uma carga horária pequena e de ter que ministrar aulas em salas lotadas. (NÚCLEO, 2012, p. 23)

Em relação à percepção dos alunos sobre seu aprendizado de LI, estes mencionam a relevância da língua inglesa para o contexto atual, dizendo ser "importante porque o inglês não é só para educação, mas também é muito procurado no mercado de trabalho" (NÚCLEO, 2012, p. 5). Desses alunos, $40 \%$ dizem fazer leitura em sala de aula e outros $20 \%$ dizem aprender gramática. 30\% desses alunos dizem conversar em inglês em sala e, quando perguntados o que isso significa, informam-nos que leem em voz alta e repetem sentenças do diálogo. Por fim, a grande maioria desses alunos relatam que os professores não utilizam qualquer outro recurso em sala de aula além do livro didático.

Nesse contexto, esses valores pressionam as identidades, garantindo a reprodução contínua dos valores negativos observados, o que constrói uma aura de desânimo geral não somente entre os professores entrevistados, mas 
também no sentido mais amplo do espaço público de ensino. Ao mesmo tempo que percebemos certa resignação e passividade de todos os lados no que se refere à possibilidade de mudança. Essa identidade vem a constituir o grupo social no qual nossos alunos se inserem como professores de LI.

\section{Identidades em questão: os processos de exclusão}

Ao discutir o papel das línguas estrangeiras do ponto de vista dos conceitos de inserção e de inclusão, as Orientaçôes curriculares para o ensino médio - língua estrangeira (OCEM-LE) trazem uma reflexão sobre a questão identitária associada ao aprendizado de LI no contexto da escola pública e nos cursos livres. O texto distingue inserção de inclusão, afirmando que a escola pública deve preocupar-se com a inclusão e não com a inserção do aluno no mundo da LI. Segundo as OCEM-LE (MEC, 2006), a inserção do aluno no mundo da língua estrangeira está para os cursos livres assim como a inclusão deve estar para o ensino público básico e regular.

As OCEM-LE explicam que o foco dos cursos livres, por um lado, é a transformação do aluno em outro, fazendo-o portar-se como este outro, assumindo uma identidade diversa daquela que o constitui originalmente. Ocorre que essa nova identidade pretendida nunca será completa, porque esse aluno será sempre um sujeito dividido entre dois mundos: o mundo a que realmente pertence e o mundo a que almeja. Essa não completude identitária, ou melhor, essa dualidade do aluno, constitui-se no motor do aprendizado nesses cursos livres, ou seja, pauta-se no desejo sempre insatisfeito do aluno pertencer definitivamente sem, contudo, pertencer completamente.

Por outro lado, na escola regular, o ensino de línguas estrangeiras deve responder às necessidades de inclusão do aluno no mundo que o rodeia, permitindo que a língua funcione como meio de construção de conhecimentos para si e para os outros por meio da reflexão sobre a cultura do outro do ponto de vista local. Para as OCEM-LE, o fracasso do ensino de línguas estrangeiras nas escolas públicas dá-se pela tentativa de reprodução do modelo dos cursos livres no espaço da sala de aula cujas condições estruturais diferem grandemente daquelas oferecidas nesses cursos. Como resultado, percebe-se um sentimento de incompletude e inferiorização em relação ao estrangeiro, o que leva ao desestímulo e ao fracasso em todos os níveis e à procura de alternativas fora desse espaço escolar.

O relato de um monitor concursado em 2012 para atuar como professor de Inglês no ensino fundamental II em uma escola pública do estado 
confirma esse ponto de vista apresentado. $\mathrm{O}$ monitor diz que não adianta tentar fazer diferente se a estrutura escolar não permite, pois a escola não oferece equipamentos para as aulas, os professores das outras matérias estão desmotivados e os alunos não entendem outra forma de aprendizado que não seja a cópia da matéria da lousa. Por fim, chega à conclusão da impossibilidade de tentar coisas novas por não haver espaço para mudanças:

Eu fiz o concurso da monitoria, passei para lecionar inglês na escola estadual. Só que eu pensei que poderia dar uma aula mais dinâmica, fugir um pouco do padrão em que eu fui ensinado nos meus primeiros anos, no ensino médio. Só que não é bem assim que acontece. Eu ensino do sexto ao oitavo ano e os alunos não demonstram muito interesse, então eu tenho que apelar para a forma escrita mesmo. Eu passo o conteúdo, eles escrevem e fica nisso. Eu queria trabalhar com filmes, mas são muitos alunos e não têm condições de trabalhar de uma forma mais diferente. (NÚCLEO, 2012, p. 42)

Percebe-se na fala do monitor a circulação dos mesmos valores constitutivos das identidades dos professores e alunos entrevistados pelo Núcleo Alagoas, ou seja, percebe-se a insatisfação aliada à desmotivação e, por fim, a resignação em fazer como todos fazem e como o próprio monitor havia aprendido a língua estrangeira.

Quando perguntado sobre o que tentava fazer de diferente em sala de aula, o monitor informou-nos que tentou falar inglês, mas ninguém entendia; tentou passar um filme, mas o aparelho não funcionava e, quando funcionou, ninguém prestou atenção. Tentou tocar uma música, mas os alunos não conheciam o cantor e, por isso, desinteressaram-se.

Percebe-se no relato das ações do monitor que, apesar da boa intenção, há uma tentativa por parte dele de aproximação do contexto do curso livre ao contexto da escola pública, o que provavelmente provocou o fracasso. $\mathrm{O}$ próprio monitor informa que é impossível trazer coisas diferentes para sala de aula porque tem 40 alunos e 12 turmas, o que o impossibilita de dar conta de preparar material suficiente, além de não ter condiçóes de controlar todos os alunos ao mesmo tempo enquanto tenta trabalhar com essas atividades. $\mathrm{O}$ sentido que advém desse trecho demonstra que as pressões originárias do contexto interferem nas práticas do monitor, fazendo com que esse graduando sucumba ao outro.

Ao refletir sobre os processos de inclusão e exclusão, Morin (2001) atribui à modernidade a construção de paradigmas compartimentados em dois 
eixos de pensamento com base nos quais se constroem campos de sentidos generalizantes e excludentes. $\mathrm{O}$ primeiro eixo, intitulado eixo da seleção, constitui-se da ordenação de conceitos pré-determinados e estabelecidos por discursos dominantes, o que tem como consequência o apagamento de outros discursos considerados de menor valor ou conflitantes com aquele central. $\mathrm{O}$ segundo eixo, intitulado de eixo das operações lógicas, estabelece as operações possíveis do pensamento com base nas categorias pré-selecionadas oriundas do primeiro eixo. Para o autor, esse conjunto impede outras formas de produção de conhecimento além daquelas possíveis na interseção entre seleção e operaçōes lógicas.

Esse ponto de vista é, de certa forma, compartilhado por Ponzio (2010) ao tratar do funcionamento das identidades em favor de agendas específicas, caracterizadas em sua grande maioria por uma estrutura de dominação e subserviência a valores advindos de interesses marcados por estruturas de consumo. Essa estrutura promove no indivíduo uma falsa sensação de poder, ocasionada pela aparente facilidade de aquisição de produtos. Entre esses produtos consumíveis, o autor cita o conhecimento como uma mercadoria que pode ser comprada e, portanto, de acesso restrito àqueles que o podem comprar.

Dessa perspectiva, podemos dizer que a escola pública e gratuita, espaço de conflitos e de diferenças, representa um não lugar de produção de conhecimentos em LI, por não ter produtos acabados a oferecer ao consumo. Em outras palavras, as identidades formadas na relação poder consumir e, portanto, pertencer / não poder consumir e, portanto, não pertencer, estabelecem eixos de sentido que transformam o espaço público e gratuito da escola no local onde as identidades constituem-se pela exclusão dada a impossibilidade de acesso ao conhecimento visto como um produto.

\section{A construção das alteridades: buscando outras identidades}

Bakhtin / Volochinov ([1929] 2010) oferecem um ponto de vista alternativo acerca de processos deterministas ocasionados pelas pressões contextuais, como nos parece ser o caso da discussão em tela, ao criticarem a relação mecanicista estabelecida entre superestruturas e infraestruturas. Os autores denominam superestruturas as organizações de poder por onde circulam valores que afetam a conduta das pessoas pertencentes a esses espaços. Já as infraestruturas constituem-se dos pequenos grupos que se formam na base dessas superestruturas por onde circulam os discursos do dia a dia, ou seja, 
sem orientação ideológica marcada pela superestrutura de dominação. A relação mecanicista enxerga os sentidos construídos dentro das infraestruturas determinados diretamente pelos valores impostos pela organização superestrutural. Sobre eles não se tem controle.

Os autores argumentam que essa situação determinista não corresponde à realidade, porque tanto as superestruturas quanto as infraestruturas são entidades abstratas, por isso, não podem determinar valores nem construir sentidos e concluem que são os participantes do funcionamento desses espaços os responsáveis pela circulação de valores, ou seja, vale dizer que no cerne desse processo estão interlocutores em diálogo. Para os autores, diálogo deve ser entendido como uma relação complexa entre locutores que respondem não somente a seus interlocutores diretos, mas principalmente às várias demandas discursivas advindas de outras direções que os pressionam por respostas. $\mathrm{O}$ diálogo orienta-se, dessa maneira, para uma infinidade de interlocutores não presentes na relação dialogal direta, mas que participam das respostas dos envolvidos. Por exemplo, o diálogo pode se orientar para a situação imediata em que os interlocutores se inserem; para os valores circulantes mais amplamente na organização; para as políticas públicas circulantes na região; para o tempo e o espaço onde os participantes se posicionam, entre outras possibilidades. Desse ponto de vista, diálogo é entendido como um processo tenso de produção de sentidos, da mesma forma que "uma faísca elétrica que só se produz quando há contato dos dois polos opostos" (BAKHTIN / VOLOCHINOV, [1929] 2010, p. 137). Esse é o motor da evolução dos sentidos dentro das organizações, o que provoca, em última instância, a própria modificação e evolução dos contextos, pois os valores aparentemente estáticos se tornam fluidos e permeáveis dentro desses espaços por meio da língua que os diz.

Ao criticar teorias que trazem a ideia da sobredeterminação do contexto sobre as identidades, Pennycook (2001) lembra que a linguagem é constitutiva das relaçôes humanas, portanto, o estudo das construçôes identitárias deve inegavelmente associar-se ao estudo da linguagem em funcionamento nas instituiçôes. Entretanto, o valor desses estudos dá-se somente no momento em que percebemos a existência de uma relação dinâmica entre situação e participantes de modo que nem os participantes do processo existem por eles mesmos, porque dependem do contexto; nem o contexto existe independentemente dos participantes que os diz, porque o dizer aponta para o contexto. $\mathrm{O}$ autor entende que as identidades nutrem-se do contexto maior ao mesmo tempo em que esse contexto maior precisa das relações estabelecidas 
pelos indivíduos para existir. Esse processo de fluidez garante a evolução tanto dos contextos quando das identidades e, consequentemente, dos sentidos.

Ponzio (2010) propõe o combate às formas de dominação que promovem movimentos de exclusão por meio da construção de alteridades firmes ligadas à libertação dos processos de sujeição do indivíduo como desenvolvimento da autopercepção da heterogeneidade constitutiva das relações humanas. $\mathrm{O}$ autor entende que cada ser humano se difere do outro porque somos constituídos por valores distintos e dinâmicos em decorrência do contínuo diálogo que se estabelece entre o contexto exterior, alheio ao indivíduo, e o contexto interior, sentimentos, vontades e percepçóes de cada um. $\mathrm{O}$ trabalho com a inclusão passa pelo reconhecimento e a aceitação do outro como diferente pelos valores diversos que o constitui. Com base nisso, o autor distingue alteridades fracas de alteridades firmes, afirmando que as alteridades fracas são aquelas constituídas em ambientes de dominação contra o qual os participantes não se opõem e onde acontecem os processos de exclusão, porque são ambientes em que os participantes enxergam-se iguais e, portanto, rechaçam o diferente. A escuta das diferenças torna-se um movimento profilático para a reversão dos valores excludentes e para a construção de alteridades firmes, que pressupõem o entendimento das singularidades pela percepção de que temos histórias, experiências e expectativas que nos humanizam e nos individualizam, distanciando-nos da homogeneização. Para o autor, ainda, as alteridades firmes promovem o fortalecimento dos grupos sociais, porque constroem identidades fortes para o enfrentamento dos contextos de dominação e subserviência. Em outras palavras, a escuta do outro permite a aceitação e o respeito às singularidades dentro dos grupos identitários a que pertencemos.

Esse ponto de vista oferece-nos uma perspectiva de trabalho com os graduandos, iniciando-se pela percepção dos próprios alunos de que há espaço para singularidades dentro de contextos aparentemente estáveis e imutáveis, apresentados a eles no espaço escolar em Alagoas. Por isso, nossa proposta de trabalho caminha em direção à tentativa de reconstrução de valores por meio do incentivo à produção de narrativas pessoais em que sentidos são constantemente trabalhados pelos próprios locutores de suas próprias narrativas. Isso permite que os participantes não somente entrem em processo de diálogo com outros tantos participantes, produzindo sentidos para eles mesmos e para os outros, mas também escutem a si mesmos, o que garante a produção de identidades mais firmes. 
Webster e Mertova (2007) opõem narrativa a história, dizendo que história tende à linearidade de fatos, promovendo a focalização de alguns eventos e o apagamento de outros muitos que se desviam do fio condutor principal. A história representa os discursos oficiais, pois reproduz e mantém o status quo por meio da unilateralidade descritiva dos eventos. A narrativa, por outro lado, tende à circularidade ocasionada pela possibilidade da reavaliação de um mesmo fato constantemente retrabalhado por meio de pontos de vistas variados, advindos de diferentes experiências humanas. Além disso, a narrativa permite ao participante a oportunidade de perceber-se único dentro de contextos generalizantes ao mesmo tempo que também percebe-se parte de um grupo com expectativas e valores comuns.

Entendemos que o trabalho de formação desses graduandos deve levar em conta não somente o contato com a realidade, mas também a perspectiva de que deve ser possível pensar outro modo de lidar com os problemas que se repetem nessa modalidade de ensino de modo que nem os ideais trazidos pelos graduandos sejam sufocados e nem os valores circulantes nessa realidade sejam impostos definitivamente a eles, fazendo com que desistam de seus ideais.

Com base nisso, organizamos nosso trabalho com a autonarrativa em três movimentos que se constituem em um grande espaço de reflexão sobre alteridades, identidades e valores. $O$ primeiro movimento busca recuperar a própria trajetória de vida até a chegada à graduação em LI, o que permite a retomada de ideais que promoveram a opção pela carreira de professor. $\mathrm{O}$ trabalho com esses ideais permite ao graduando perceber-se único em um primeiro momento, mas quando confrontado com outras narrativas, percebese também e ao mesmo tempo entre outros com algumas semelhanças e também algumas diferenças. Um graduando participante desse processo produz uma narrativa contundente sobre esse evento:

Morava na divisa de Pernambuco e Alagoas, no sertão. Não tínhamos energia elétrica, por isso, a vida era muito simples [...] Como no povoado só havia até a quarta série, precisaria sair do povoado para continuar estudando, mas meu pai não permitia. No ano 2000, chegou a energia e a televisão, daí a vida mudou porque o povoado ficou pequeno demais. Meus irmãos vieram para Maceió, conseguiram emprego e eu vim depois para cuidar da casa deles. Fui estudando e agora estou aqui. Quero me formar para voltar e ensinar no meu povoado. Dar oportunidade aos outros de também saírem e procurarem outras possibilidades. Sabe como é... (NÚCLEO, 2012, p. 50) 
Bakhtin ([1979] 2003) descreve os seres humanos como seres em devir, dizendo que pautamos nossos atos pelos valores visados em um horizonte para o qual voltamos constantemente nossos olhares nem sempre exatamente correspondentes àqueles valores circulantes no ambiente onde estamos inseridos. A narrativa do aluno aponta tanto para o contexto onde se insere quanto para o horizonte de valores visados por ele. $\mathrm{O}$ graduando descreve o contexto em "como no povoado só havia até a quarta série, precisaria sair do povoado para continuar estudando, mas meu pai não permitia”. Percebemos também o movimento de oposição do aluno a isso, ao dizer que "no ano 2000, chegou a energia e a televisão, daí a vida mudou porque o povoado ficou pequeno demais". O horizonte visado está expresso na vontade de estudar, na necessidade de formar-se e no ideal de tornar-se professor para ensinar em uma sala de aula: "quero me formar para voltar e ensinar no meu povoado. Dar oportunidade aos outros de também saírem e procurarem outras possibilidades". Apesar de diferenciar-se de outras falas, essa narrativa apresenta traços comuns com outras narrativas produzidas, por exemplo, o contexto difícil, a vontade de mudar e o desejo de poder fazer diferente. Esses valores somente podem ser percebidos quando explicitados, socializados e discutidos entre os participantes.

O segundo movimento narrativo refere-se à produção de relatos reflexivos sobre participações em aulas de LI em escolas da região. Nessa narrativa, percebe-se certo distanciamento do graduando das práticas da professora observada, que extrapola a simples descrição da aula:

Nas aulas a professora parece estar mais preocupada em passar o conteúdo programático com bastante gramática sem se importar com a interação dos alunos. Ela escreve bastante no quadro e os alunos automaticamente copiam em seus cadernos como se essa prática fosse um procedimento automatizado. As respostas das atividades aplicadas em sala de aula são dadas no quadro pela própria professora sem nenhuma interação com os alunos, eles apenas copiam as respostas ditadas e escritas no quadro pela professora, como se a aula fosse composta apenas de regras a serem seguidas. (NÚCLEO, 2012, p. 45, grifos nossos)

Os trechos grifados trazem muito mais do que a descrição de fatos. Neles percebemos a inserção de outro ponto de vista sobre a descrição dessas práticas. Os quantificadores "mais", "bastante" e "apenas" em "parece estar mais preocupada em passar o conteúdo programático com bastante gramática”; "ela escreve bastante no quadro"; e "os alunos, eles apenas copiam"; além do termo 
“automatizado" em "como se essa prática fosse um procedimento automatizado" demonstram que o graduando parece constituir-se por meio de uma identidade diversa dos valores apresentados nas práticas descritas por ele mesmo que, em última instância, advêm do grupo a que esse professor pertence, assemelhando-se ao relato sobre ensino tradicional apresentado anteriormente.

A possibilidade de perceber-se outro pelo contato com a realidade abre espaço para o terceiro movimento, que acontece pela afirmação da alteridade do graduando frente ao contexto educacional imposto, ao mesmo tempo em que também reconhece sua própria identidade como professor. A narrativa a seguir, feita ao fim do processo que engendrou os dois movimentos anteriores, é um exemplo da vontade de mudança incorporada nos valores apresentados. A percepção acerca da LI como agente transformador nos contextos sociais em que se instaura parece constituir-se no motor da narrativa:

Isso me permitiu ver o quanto o ensino de língua inglesa é importante na vida do indivíduo, e o quanto esse ensino está ligado a questôes sociais. Vejo como o ensino de língua inglesa pode ser um fator de inclusão não apenas para fins linguísticos, mas também socioculturais. Entendo que ser professor de língua estrangeira implica uma responsabilidade muito grande na sociedade. Pois além [de] ensinar a língua inglesa em seu conteúdo, temos uma responsabilidade bem maior, que é a de transformar indivíduos em cidadãos com formação crítica. (NÚCLEO, 2012, p. 56)

Consideramos que este graduando está pronto para inserir-se no espaço escolar público para ensinar essa língua. A narrativa demonstra que o aluno percebe a LI como possibilidade real de acesso, inclusão e mudança, quando afirma que "esse ensino está ligado a questôes sociais". Também percebe-se como agente de uma ação "bem maior, que é a de transformar indivíduos em cidadãos com formação crítica”. A narrativa apresentada mostra que o graduando transcende o mero conhecimento formativo acerca das práticas de ensino e aprendizagem, posicionando-se frente ao mundo que vai enfrentar, o que implica dizer que o conhecimento prático deixa de ser um fim em si mesmo no curso de formação para tornar-se uma consequência do lugar assumido pelo graduando frente ao ensino da língua. 


\section{Considerações finais}

Freire (1993) considera que educação e política andam juntas, porque ambas exercem uma ação transformadora sobre o outro. Isso quer dizer que todo ato de educar é uma ação política, assim como toda ação política implica a modificação do outro, o que é o cerne do processo educativo. Desse modo, não existe lugar para práticas mecanicistas que meramente transmitem informações sem produzir qualquer sentido novo para o educando e para o educador, além do produto acabado do conteúdo ensinado. $\mathrm{O}$ autor utiliza os termos sujeito e objeto para explicar que as práticas mecanicistas estabelecem uma relação determinista entre educador e educando, pois este é visto pelo educador como um objeto a ser moldado. $\mathrm{O}$ resultado dessa relação pende para a submissão e a dominação, colocando o educador tanto como sujeito quanto como objeto moldado em favor de interesses específicos.

Para Freire (1993), o processo educativo deve ser composto de sujeito educador e sujeito educando, ambos situados historicamente e em constante modificação mútua, promovendo a construção de redes sólidas de conhecimento e respeito, porque, em última instância, a educação se dá entre seres humanos, ponto de vista com o qual concordamos. Somente assim, esses sujeitos se tornam agentes modificadores da sociedade, afastando-se da dominação imposta por posturas dogmáticas e fechadas. Segundo o autor,

[r] essaltamos inicialmente a sua condição de ser histórico-social, experimentando continuamente a tensão de estar sendo para poder ser e de estar sendo não apenas o que herda mas também o que adquire, e não de forma mecânica. Isso significa ser o ser humano, enquanto histórico, um ser finito, limitado, inconcluso, mas consciente de sua inconclusão. Por isso, um ser ininterruptamente em busca, naturalmente um ser em processo. (FREIRE, 1993, p. 10)

Com isso em mente, concluímos dizendo da impossibilidade da garantia de que nossa proposta formativa concretamente traga resultados para o contexto educativo do estado a curto e médio prazos. Também não podemos afirmar que o processo formativo perdure no graduando ao se tornar professor em serviço em decorrência das pressões identitárias que certamente sofrerá em suas práticas dentro do espaço escolar onde atuará. Podemos, entretanto, reafirmar nossa crença no sujeito freireano como agente transformador e na ação política como prática formativa, na interação como produtora de sentidos e na fluidez dos contextos por onde circulam esses sujeitos. 


\section{Referências}

AMORIM, M. O pesquisador e seu outro: Bakhtin nas ciências humanas. São Paulo: Musa Editorial, 2002.

BAKHTIN, M. / VOLOCHINOV, V.N. Discurso na vida e discurso na arte. Trad. Carlos Alberto Faraco e Cristóvão Tezza. In: . Freudianism: A Marxist Critique. New York: Academic Press, [1926] 2000.

BAKHTIN, M. Estética da criação verbal. 4. ed. Trad. Paulo Bezerra. São Paulo: Martins Fontes, [1979] 2003.

BAKHTIN, M. / VOLOCHINOV, V.N. Marxismo e filosofia da linguagem: problemas fundamentais do método sociológico na ciência da linguagem. 14. ed. Trad. Michel Lahud e Yara Frateschi Vieira. São Paulo: Hucitec, [1929] 2010.

FAIRCLOUGH, N. Discourse and Social Change. Cambridge (UK): Polity, 2003.

FREIRE, P. Politica e educação. São Paulo: Vozes, 1993.

IBGE - INSTITUTO BRASILEIRO DE GEOGRAFIA E ESTATÍSTICA. Indicadores Sociais Municipais 2010: incidência de pobreza é maior nos municípios de porte médio. Disponível em: <http://censo2010.ibge.gov.br/ noticias-censo? view $=$ noticia $\& i d=3 \& i d n o t i c i a=2019 \& b u s c a=1 \& \mathrm{t}=$ indicadores sociais-municipais-2010-incidencia-pobreza-maior-municipios-porte-medio $>$. Acesso em: 27 nov. 2013.

IDEB - ÍNDICE DE DESENVOVIMENTO DO ENSINO BÁSICO. Resultados e metas. 2012. Disponível em: <http://ideb.inep.gov.br/resultado/ resultado/resultado.seam?cid=1609034>. Acesso em: dez. 2012.

MEC - MINISTÉRIO DA EDUCAÇÃO. Orientaçôes curriculares para o ensino médio. Brasília (DF): Ministério da Educação / Secretaria de Educação Básica, 2006. v. 1: Linguagens, códigos e suas tecnologias.

MORIN, E. Os sete saberes necessários à educação do futuro. São Paulo: Cortez, 2001.

NÚCLEO ALAGOAS. Projeto Nacional - Núcleo Alagoas - UFAL - FALE Coleta 2012.1. Maceió, 2012. Mimeografado.

PENNYCOOK, A. A Linguística Aplicada dos anos 90: por uma Linguística Aplicada crítica. In: SIGNORINI, I.; CAVALCANTI, M. Linguistica Aplicada e transdisciplinaridade: questões e perspectivas. Campinas: Mercado de Letras, 1998. PENNYCOOK, A. Critical Applied Linguistics - A Critical Introduction. London; New Jersey: LEA, 2001.

PONZIO, A. Procurando uma palavra outra. São Carlos: Pedro e João Editores, 2010. 
SEPLANDE. Alagoas em números: 2011. Maceió: Governo de Alagoas / Secretaria do Estado do Planejamento e do Desenvolvimento Econômico, 2011. Disponível em: <http://informacao.seplande.al.gov.br/publicacoes/2011121/ alagoas-numeros-2011>. Acesso em: jul. 2012.

TODOS PELA EDUCAÇÃO. [Educação no Brasil - Busca comparativa Brasil/ Alagoas]. Disponível em: <http://goo.gl/XFTzAI>. Acesso em: jan. 2012.

WEBSTER, L.; MERTOVA, P. Using Narrative Inquiry as a Research Method. London; New York: Routledge, 2007. 